\title{
Alice Clark-Wehinger, William Shakespeare et Gérard de Nerval. Le théâtre romantique en crise 1830-1848
}

\section{Rita Severi}

\section{(2) OpenEdition}

1 Journals

\section{Edizione digitale}

URL: https://journals.openedition.org/studifrancesi/46127

DOI: 10.4000/studifrancesi.46127

ISSN: 2421-5856

\section{Editore}

Rosenberg \& Sellier

\section{Edizione cartacea}

Data di pubblicazione: 1 octobre 2007

Paginazione: 469

ISSN: 0039-2944

\section{Notizia bibliografica digitale}

Rita Severi, «Alice Clark-Wehinger, William Shakespeare et Gérard de Nerval. Le théâtre romantique en crise 1830-1848», Studi Francesi [Online], 152 (LI | II) | 2007, online dal 30 novembre 2015, consultato il 24 novembre 2021. URL: http://journals.openedition.org/studifrancesi/46127 ; DOI: https://doi.org/ $10.4000 /$ studifrancesi.46127

Questo documento è stato generato automaticamente il 24 novembre 2021.

\section{(c) $(1) \ominus$}

Studi Francesi è distribuita con Licenza Creative Commons Attribuzione - Non commerciale - Non opere derivate 4.0 Internazionale. 


\title{
Alice Clark-Wehinger, William Shakespeare et Gérard de Nerval. Le théâtre romantique en crise 1830-1848
}

\author{
Rita Severi
}

\section{NOTIZIA}

ALICE CLARK-WEHINGER, William Shakespeare et Gérard de Nerval. Le théâtre romantique en crise 1830-1848, Paris, L'Harmattan, 2005, pp. 296.

1 L'autore si propone di spaziare nel vasto mondo comparativo della letteratura romantica analizzando, in un primo momento, gli articoli che il giovane Nerval dedicò al teatro, alle traduzioni drammatiche e agli adattamenti per il palcoscenico, soprattutto di provenienza inglese e, in un secondo momento, agli effetti che questo teatro, prevalentemente d'importazione, ebbe sui letterati e sul pubblico. Come già aveva notato con la consueta perspicacia Théophile Gautier nella sua Histoire $d u$ romantisme, dalla fine degli anni Venti, in Francia, s'instaura una moda letteraria che guarda con grande favore verso l'Inghilterra e praticamente inizia con la valorizzazione delle opere di Lord Byron, con la divulgazione dei romanzi di Walter Scott, nonché della vita che lo scozzese aveva dedicato a Napoleone (1826), con la introduzione dei modelli poetici di Milton e del grande teatro di Shakespeare.

2 La critica giornalistica nervaliana, concentrata esclusivamente sui testi drammatici e sulle rappresentazioni teatrali, si prolunga per il periodo che va dal 1830 fino al 1847, durante il quale lo scrittore collaborò con articoli firmati e anonimi ai seguenti giornali e riviste: «Écho de la littérature», L'Illustration, Journal de comédiens, Le Monde illustré, Le Monde dramatique, Le National, La Nouvelle Minerve, Le Pionnier, La Quotidienne, La Revue britannique, Revue des deux mondes, Revue des théâtres, e Théâtres de Paris. La collaborazione più intensa avvenne con La Revue britannique, alla quale, dal 1830 fino al 1847, in modo discontinuo, Nerval inviò articoli che affrontavano argomenti diversi, 
dalla situazione dei teatri inglesi nel 1830, ai cantanti italiani, alle ballerine inserite nelle rappresentazioni shakespeariane, al Latréaumont, dramma in cinque atti messo in scena da P. Dinaux e E. Sue al Théâtre Français il 10 novembre 1840.

3 Come dimostra l'autore, con argomentazioni molto persuasive e una documentazione dettagliata del contesto giornalistico e letterario, Nerval operava da apri-pista non riconosciuto, consapevole della crisi che aveva investito il teatro francese, disposto ad andare controcorrente, con critiche costruttive che presentavano esempi di teatro vitale, guardando soprattutto ai modelli inglesi, tra i quali predilesse il grande spettacolo del dramma shakespeariano.

4 Il saggio è corredato da utilissimi indici dei nomi, dei temi e delle opere citate, ma, dispiace dirlo, la bibliografia è molto datata. 